\title{
A Fokker-Planck neuronal network model to capture mean firing rate and pair-wise correlations in large-scale neuronal networks
}

\author{
Chin-Yueh Liu ${ }^{1 *}$, Duane Q Nykamp² \\ From Nineteenth Annual Computational Neuroscience Meeting: CNS*2010 \\ San Antonio, TX, USA. 24-30 July 2010
}

\begin{abstract}
A Fokker-Planck neuronal network model is presented. This model can be efficiently implemented to investigate how the mean firing rate and pair-wise correlations in each population depend on certain first and second order statistical patterns of connectivity. To capture pair-wise correlations among neurons in each population, we derive the evolution equations of the joint population density $\rho\left(\mathrm{v}_{1}, \mathrm{v}_{2}, \mathrm{t}\right)$ of the voltage of any pair of neurons in the population. By assuming that the input to any pair of neurons is a multivariate Poisson point process, we obtain partial differential-integral equations for each population, but closure of this system of equations requires inferring higher order statistics of activity. We simplify the framework by applying a diffusion approximation and obtain Fokker-Planck equations for each population. We prove that, under some assumptions, the coupling scheme to derive network equations can be based on only the first and second order statistics of activity and connectivity, without the need to infer higher order statistics. Also, fast numerical methods can be devised to solve this simple network model. We test the validity of our network model by comparing the numerical solutions to Monte Carlo simulations under various network configurations. Finally, we discuss the success and failure of our Fokker-Planck neuronal network model.
\end{abstract}

\footnotetext{
Author details

${ }^{1}$ Department of Applied Mathematics, National University of Kaohsiung, Kaohsiung, Taiwan. ${ }^{2}$ School of Mathematics, University of Minnesota, Minneapolis, Minnesota, 55455, USA.
}

\footnotetext{
* Correspondence: cyliu1025@nuk.edu.tw

${ }^{1}$ Department of Applied Mathematics, National University of Kaohsiung, Kaohsiung, Taiwan
}

Published: 20 July 2010

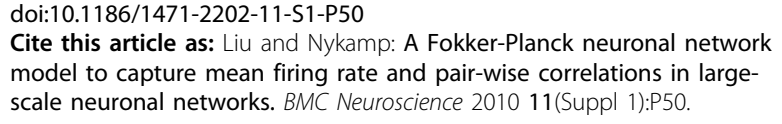

\section{Submit your next manuscript to BioMed Central and take full advantage of: \\ - Convenient online submission \\ - Thorough peer review \\ - No space constraints or color figure charges \\ - Immediate publication on acceptance \\ - Inclusion in PubMed, CAS, Scopus and Google Scholar \\ - Research which is freely available for redistribution \\ Submit your manuscript at www.biomedcentral.com/submit}

